\title{
Da licenciatura à sala de aula: o processo de aprender a ensinar em tempos e espaços variados
}

\section{From Teacher's education course to classroom: the process of learning how to teach at varied times and spaces}

\author{
Rosemara Perpétua Lopes ${ }^{1}$
}

\begin{abstract}
RESUMO
Formação de professores é um desafio que ultrapassa fronteiras de espaço e tempo. No caso da formação inicial, as dificuldades de articular necessidades formativas oriundas do campo de atuação às possibilidades dos cursos que formam o professor se mantêm. Buscando contribuir para minimizá-las, realizou-se uma investigação, cujos objetivos foram: investigar processos de aprendizagem da docência e evidenciar concepções de futuros professores sobre a sua profissão. Formulou-se um questionário com perguntas abertas, respondido por vinte estudantes do último ano de licenciatura de uma universidade pública do interior paulista, de cursos distintos. Os dados foram analisados em seis eixos temáticos, resultando em significativas constatações, das quais se destaca a falta de saberes relativos à especificidade da profissão docente e ao contexto sócio-histórico no qual ela acontece, comprometendo a ação futura do professor e, consequentemente, a aprendizagem do aluno da escola básica. Cabe, pois, repensar a formação docente, numa época em que seu redimensionamento por meios tecnológicos é possível.

Palavras-chave: formação inicial de professores; licenciatura; saberes e aprendizagens docentes.
\end{abstract}

1 Pedagoga. Mestranda em Educação na Faculdade de Ciências e Tecnologia da Universidade Estadual Paulista - UNESP, Campus de Presidente Prudente. Investiga Formação Inicial de Professores, na Linha de Pesquisa "Tecnologias de Informação e Comunicação e Educação". 


\begin{abstract}
Teacher education is a challenge that oversteps borders of space and time. In case of the initial education the difficulties of enunciating formal necessities arising from the working field to the possibilities of the courses that educate teachers. In search to contribute to minimize them this investigation aims: to investigate the teachers learning process and to evidence notion of future teachers on their career. A questionnaire of open questions was answered by twenty students of the last term in different major curses at a public university of São Paulo State countryside. The data were analyzed based in six thematic subjects, resulting in significant evidences from which one emphasizes the lack of background related to the specificity of the teaching career as well as to the historic-social context it happens committing future action of teachers and, consequently, the student learning in basic schools. One should thus re-think the teacher formation within a time in which its re-dimension by means of technological means is possible.

Keywords: teacher initial education; major; teaching background and knowledge.
\end{abstract}

\title{
Introdução
}

Marcado por inovações tecnológicas e científicas, o século XXI oferece novos desafios ao profissional docente. No que tange à formação de professores, esta vem sendo objeto de estudos e pesquisas há algumas décadas (LELIS, 2001).

$\mathrm{Na}$ licenciatura, o futuro professor adquire conhecimentos que compõem seus quadros referenciais para a profissão (MIZUKAMI, 1996). Ainda que a formação inicial sozinha não dê conta de formar o professor para atuar num ambiente marcado pela imprevisibilidade e por constantes mudanças, pode propiciar a construção de bases sólidas para aprendizagens futuras.

Essas conjecturas levam a refletir sobre o papel da licenciatura num processo de formação que envolve mais do que a dimensão profissional do futuro professor. $\mathrm{O}$ estudante que ingressa na universidade buscando ser professor está motivado, tem objetivos e expectativas, tem também concepções trazidas do período de escolarização (MARCELO, 1998). Ele acredita que a universidade fará dele um professor. Ao longo do curso, suas crenças vão mudando. Transformam-se em meio a um processo no qual se faz necessário distinguir o 
que é preciso conhecer para ser professor. Na escola, logo nas primeiras aulas, as dificuldades do professor iniciante em desenvolver aquilo que caracteriza a sua função tornam-se evidentes (LIMA, 2004). Necessitando lidar com o fenômeno educativo em seus variados aspectos, conseguirá o futuro professor ao menos reconhecê-lo?

Sob o prisma dos variados fatores que influem, permeiam e caracterizam o processo educativo, dominar o conteúdo de ensino é condição fundamental, mas não suficiente ao professor, especialmente nos dias atuais. Adotando a premissa de que o pensar orienta o fazer docente (MIZUKAMI, 1986; MARCELO GARCÍA, 1997), prática educativa e teorias educacionais devem caminhar juntas na formação inicial do professor. Nesse contexto, parece no mínimo estranho que um curso cuja especificidade é formar professores não os torne minimamente preparados para lidar satisfatoriamente com o trabalho em sala de aula, trabalho que, nos dias atuais, tem seu grau de complexidade ampliado por novas propostas e inovações educacionais (MANTOAN, 2001; BARRETO, 2003).

$\mathrm{O}$ exposto motivou a pesquisar quais saberes, concepções e expectativas sobre a profissão docente têm alunos de cursos de Licenciatura em Letras e em Matemática.

\section{Objetivos e metodologia da pesquisa}

Entendendo que os saberes sobre a docência e sua especificidade não devem figurar como pontuais em cursos de licenciatura que formam o professor para atuar nos anos finais do ensino fundamental e no ensino médio, buscou-se: investigar processos de aprendizagem da docência vividos em cursos de licenciatura e evidenciar concepções de estudantes do quarto ano de licenciatura sobre a profissão docente.

Estudantes de cursos de graduação de uma universidade pública do interior paulista foram eleitos como sujeitos da pesquisa, sendo dez do Curso de Licenciatura em Letras e dez do Curso de Matemática, modalidade Licenciatura. Tais cursos foram selecionados mediante o critério "dificuldades de ensinoaprendizagem de Língua Portuguesa ou de Matemática" na Educação Básica.

Para a coleta de dados, formulou-se um questionário contendo oito perguntas abertas. Optou-se por perguntas abertas para não sugerir de antemão respostas ao sujeito e não "represar" sua escrita (BARROS; LEHFELD, 2000). Os dados foram coletados em tempo real, em sala de aula, mediante a colaboração de professores dos cursos envolvidos, exceção feita aos alunos do 
Curso de Letras do período noturno, sendo analisados nos eixos: 1) Professor: da teoria à prática da sala de aula; 2) A relevância das concepções do professor à sua prática educativa; 3) O papel do professor na gestão escola; 4) Saberes e formação docente; 5) Formação e trabalho docente; 6) Experiência docente: formação que transcende os estreitos limites da sala de aula da universidade. Os sujeitos da pesquisa são identificados pelas letras A, M, L, D e N, onde: A: aluno, M: Matemática, L: Letras, D: diurno, N: noturno.

Sobre os eixos, no primeiro, analisa-se a preocupação dos futuros professores pesquisados sobre qual deve ser a preocupação de um professor em seu primeiro dia de aula, a visão que têm do professor como educador ou profissional ou ambos, a relação do futuro professor com o fenômeno aula e suas interfaces (ensino, educação, conhecimento, homem, sociedade etc.); no segundo, educação e ensino como conceitos centrais e globais constitutivos de outros; no terceiro, a postura do sujeito numa situação que em que lhe cabe assumir ou não tarefa tradicionalmente atribuída a dirigentes de escola; no quarto, saberes aprendidos no curso de licenciatura, saberes almejados e saberes considerados importantes para a profissão; no quinto, conhecimentos necessários ao professor para o ensino de conteúdos específicos, no caso, Língua Portuguesa ou Matemática; no sexto, experiências do sujeito como professor e/ou estagiário.

\section{Discussão e análise de dados}

Os eixos foram construídos sob enfoques diferenciados, de modo a evidenciar concepções, saberes e vivências do futuro professor, evidenciando, ainda, em última instância, seu preparo para a docência. Dados os limites deste trabalho, as análises desenvolvidas em cada eixo serão apresentadas de forma sintética, a seguir.

\section{Professor: da teoria à prática da sala de aula}

Esse eixo abarca as concepções dos futuros professores sobre: a preocupação central de um professor em seu primeiro dia de aula; o professor como educador ou profissional; uma aula diferente. Tais concepções são abaixo explicitadas. 
A preocupação central de um professor em seu primeiro dia de aula

Para $60 \%$ dos estudantes pesquisados, o aluno é a grande preocupação do professor. Sobre o seu primeiro dia em uma escola como professor, escreveu o estudante AMD5: "passar segurança aos alunos é minha maior preocupação. Mostrar a eles que eu quero ser amigo deles, que eu não quero ser somente o professor 'carrasco' de matemática" (grifo do estudante). O estudante AMN5, por sua vez, escreveu: "poder expor o conteúdo de maneira simples e objetiva, que eu possa sair da sala de aula com um (sic) sementinha plantada e colher excelentes resultados". Este último evidencia bem mais do que a sua primeira preocupação num primeiro dia de aula. A postura assumida pelo professor em sala de aula é focalizada por um dos sujeitos, que assim se expressou: "é por meio da postura que o professor assume que ele conseguirá dirigir sua aula, refletindo sobre suas escolhas e atitudes" (ALD3).

\section{Professor: educador ou profissional?}

Aos olhos dos estudantes do Curso de Matemática, Licenciatura, a palavra “educador" é a que melhor define a função social e educacional do professor ( $70 \%$ dos pesquisados); aos olhos dos estudantes do Curso de Licenciatura em Letras (60\% dos pesquisados), o professor é um educador e também um profissional. No discurso dos sujeitos da pesquisa, transparece a ideia de que o educador tem uma missão e o profissional, por sua vez, tem uma carreira. Para um dos estudantes, "o que só quer dinheiro é profissional. O que quer ser um verdadeiro professor educa e desperta o pensar do aluno" (AMD4). Na perspectiva de um outro, "o professor deve ser um educador, no sentido de lutar até o fim para que o conteúdo fosse [sic] transmitido e ensinado. Porém, muitas vezes, o professor acaba por escolher ser um profissional, pois não há respaldo e condições para que seu sonho (ou vontade) se realize" (AMN3). De acordo com Libâneo (2004, p. 75), "o professor é um profissional cuja atividade principal é o ensino".

\section{O fetiche de uma aula diferente}

Uma "aula diferente" foi submetida à apreciação dos sujeitos da pesquisa. Foi-lhes perguntado se um professor que propõe dialogar com os alunos sobre assuntos do interesse deles seria uma boa opção metodológica. Os futuros professores entenderam que "fugir" do tradicional em sala de aula era uma boa alternativa: 
Vejo a iniciativa como um incentivo para captar a atenção de todos os alunos, fazendo-os pensar e, porventura, participar. No entanto, penso que tal tipo de iniciativa deva ser raríssima porque a escola deve [ser] um local de aprendizado e não um local onde os alunos fazem o que querem fazer, falam sobre o que querem conversar. (ALN3)

As respostas dadas à pergunta sobre uma aula diferente foram analisadas sob os aspectos: identifica ou não a perspectiva teórica subjacente à prática do professor; aprova ou não a proposta; menciona ou não a ausência de abordagem de conteúdos de ensino. Constatou-se que $60 \%$ dos pesquisados aprovaram a iniciativa do professor, mas não identificaram a orientação teórica subjacente à sua prática ou fizeram menção à ausência de conteúdos; $35 \%$ aprovaram, fizeram menção à falta de conteúdo, mas não identificaram ou fizeram qualquer referência aos pressupostos que teriam motivado uma aula diferente. Em momento algum, os sujeitos pesquisados referiram-se a teorias educacionais que pudessem estar orientando ou promovendo conceitualmente a aula diferente.

Ao escreverem sobre a prática educativa do professor que protagonizou a tal aula, os estudantes do último ano de licenciatura centraram-se em "o que ele quer com isso" (objetivos) e não em "o que o levou a propor isso" (orientação teórica, princípios epistemológicos subjacentes). A relação entre realidade (prática escolar) e conhecimentos acadêmicos (teorias educacionais) é compreendida por Lima e Reali (2002, p. 228) do seguinte modo: "à luz dos conhecimentos acadêmicos pode-se entender melhor a realidade, mas à luz desta pode-se melhor entender aqueles". Para Libâneo (2001, p. 192), “a profissão de professor combina sistematicamente elementos teóricos com situações práticas reais". Nesse sentido, considera que "os alunos precisam conhecer o mais cedo possível os sujeitos e as situações com que irão trabalhar”.

\section{A relevância das concepções do professor à sua prática educativa}

Educação e ensino revelaram-se um enigma aos estudantes de licenciatura do último ano. Os estudantes do Curso de Matemática Licenciatura e os estudantes do Curso de Licenciatura em Letras veem a educação como algo mais abrangente do que o ensino ("a educação é um conceito amplo" [ALD1], "a educação não engloba apenas o ambiente estudantil" [ALD3] etc.) que, nesse contexto, aparece relacionado à sala de aula, à escola, à educação formal, ao exercício do magistério. Nas palavras de um estudante, ensino é a "forma com que se transmite os conhecimentos necessários" [ALD1] (grifo nosso).

Ao buscarem caracterizar e/ou diferenciar educação e/de ensino, apenas 
discutiram questões do âmbito de cada um deles, sem abordá-los diretamente. A dificuldade dos sujeitos em relação à temática proposta tem paralelo com o enunciado por um deles: "[...] na vida acadêmica nunca ninguém me disse a diferença se houver" (AMN2). De acordo com Mizukami (1986), há diferentes modos de se conceber educação e ensino. Trata-se de processos complexos abordados sob diferentes perspectivas, a saber: tradicional, cognitivista (que chegou à escola por volta de 1980 e nela se encontra presente fortemente até os dias atuais), comportamentalista (Skinner), sociointeracionista (Paulo Freire), humanista (Carl Rogers), entre outras. Não há, portanto, uma concepção única de educação, de ensino ou de aprendizagem. O importante é saber que existem diferentes abordagens e em que elas se diferenciam. Também é preciso ter clareza a respeito daquela que se adota.

Do ponto de vista da abordagem cognitivista, por exemplo, aprender implica assimilar o objeto a esquemas mentais. A aprendizagem verdadeira se dá no exercício da inteligência. É necessário que se considere o aprender a aprender; o ensino, por sua vez, está baseado no ensaio e no erro, na pesquisa, na investigação, na solução de problemas por parte do aluno, e não em aprendizagem de fórmulas, nomenclaturas, definições etc. O ensino dos fatos deve ser substituído pelo ensino de relações. Do ponto de vista da abordagem tradicional, os alunos são instruídos pelo professor e a aprendizagem é vista como produto, implicando em memorização e reprodução de conteúdos (MIZUKAMI, 1986).

\section{O papel do professor na gestão escola}

Buscando depreender as concepções dos estudantes pesquisados sobre o papel do professor na escola, foi-lhes proposta uma situação em que, na condição de professor, numa situação específica, eram convidados a ocupar o lugar de dirigente de escola (coordenador pedagógico ou diretor de escola). Em resposta, constatou-se o que segue: $80 \%$ dos estudantes do Curso de Licenciatura em Letras responderam que o papel do professor está restrito à sala de aula; quanto aos estudantes do Curso de Matemática, verificou-se um equilíbrio - $60 \%$ responderam o que respondeu a maioria dos estudantes do Curso de Licenciatura em Letras e $40 \%$ responderam que o papel do professor na escola se estende para além da sala de aula.

O enunciado a seguir sintetiza as concepções da maioria dos sujeitos a respeito: "[...] Se a ausência dele estivesse relacionada a um problema sério, como saúde ou morte, eu, como professor, poderia até aceitar cumprir essa função" (ALD2, grifo nosso). Entre concepções e humores, as produções escritas assumem contornos singulares, denotando ênfase, ironia, indignação. Na intenção de comunicar uma ideia, alguns estudantes são enfáticos: "Eu responderia que 
não poderia receber, pois tenho uma aula [para] dar" (AMD3). Outros, irônicos: "Claro! Afinal devemos deixar bem claro a situação da escola como ela se encontra uma vez que já percebemos uma falha já na recepção do agente" (AMD4). Houve também quem expressasse desabafo, indignação.

Esta pergunta é muito boa, mas ao invés de ser apenas um agente da secretaria municipal de Educação, o visitante podia ser o governador do Estado ou o ministro da educação ou o secretário da educação. Desse modo, eu iria repetir todo o descurso [discurso] apresentado por ele (durante a sua candidatura), com todas as suas retóricas e elogios, do ensino implantado por ele, enquanto passeava pelo refeitório (farto de comida), salas de informática (com computadores suficientes à demanda), salas de laboratório (bem equipados com aparelhos modernos) e as classes (formadas por alunos conscientes de que estudar é bom e que lhe fará bem no futuro). Ah! não poderia deixar de falar que se não fosse o ilustríssimo (ele), a escola, ou melhor a educação estaria falida. (AMN3)

A realidade atual da escola é retratada pelo professor aprendiz, num misto de provocação e busca de respostas.

Falaria com o agente sem nenhum problema. Só não sei se utilizaria o coletivo para apresentar os trabalhos organizados na escola. A escola é respondida em grupos mas muitos destes desunidos e pouco interessante ao trabalho dos outros. Você aí que está lendo, já viu professor com walkman nos ouvidos nas reuniões de HTPC? Vendo por este lado, crianças agitadas só estão mostrando a euforia de estar num grupo bem mais coletivo que os próprios professores. Quem é aprendiz, quem é professor? (AMN4)

Instado a opinar sobre uma situação envolvendo gestão escolar, um dos sujeitos escreveu: "Diria que não poderia porque, talvez, pudesse não estar a par de TODOS os trabalhos realizados pela escola (já que em uma escola deve haver vários projetos pedagógicos), deixando, assim, a escola com uma visão 'deturpada' aos olhos do agente" (ALN1). Nota-se que o estudante foi enfático ao utilizar o pronome indefinido "todos". Pelo que se observa, o fator decisivo em sua recusa seria "não estar a par de todos os trabalhos realizados pela escola". Nesse caso, a ação teria sido motivada mais por fatores externos ao sujeito, como o acesso aos trabalhos realizados na escola, do que por suas concepções. 
As concepções evidenciadas indicam que, para esse estudante, professor não se ocupa da gestão da escola, instituição na qual cada um tem uma função específica, para a qual são necessários conhecimentos igualmente específicos. Isso remete ao modelo de gestão fundamentada no paradigma tradicional ou burocrático previsto por Alonso (2003). Ao discorrer sobre uma situação envolvendo gestão escolar, os estudantes utilizaram argumentos vão daquilo que "o professor não tem" (a exemplo de conhecimentos e técnicas e de informações sobre todas as atividades desenvolvidas na escola) à especificidade da função de cada um dentro do espaço escolar. Em relação a este assunto, Libâneo (2004, p. 124) esclarece que "concepções de gestão escolar refletem diferentes posições políticas e concepções do papel da escola e da formação humana na sociedade". De modo geral, os futuros professores discorreram sobre uma situação envolvendo gestão escolar sem sequer reconhecê-la como tal.

\section{Saberes e formação docente}

Os futuros professores de Matemática lançam um olhar crítico sobre a sua formação, evidenciando a necessidade de aquisição de saberes que formem o professor e não apenas o matemático ou o linguista, assim como a necessidade de participação ativa na formação. Isso se aplica em especial aos estudantes do Curso de Matemática, que se mostraram pouco à vontade para discorrer sobre as próprias aprendizagens.

Em se tratando dos saberes do professor, Tardif (2002, p. 241) esclarece que formação específica requer conhecimentos específicos. Nesse sentido, considera que na formação do professor são ensinadas "teorias sociológicas, docimológicas, psicológicas, didáticas, filosóficas, históricas, pedagógicas etc., que foram concebidas, a maioria das vezes, sem nenhum tipo de relação com o ensino nem com as realidades cotidianas do ofício de professor". A perspectiva do autor encontra ressonância na dos estudantes pesquisados, ao evidenciarem a necessidade de aprendizagens e não apenas de teorias dissociadas da realidade verificada em seu campo de atuação.

O enunciado "como conseguir verter o conhecimento teórico aprendido em uma eficiente prática pedagógica (como cruzar esse abismo que separa esses dois lados)? (ALD2)" leva a refletir sobre modelos de formação do professor, especificamente aquele cujo eixo é a lógica das disciplinas curriculares, conforme previsto por Tardif. As palavras do estudante pesquisado comunicam que a existência do que chamou de "abismo" entre conhecimento teórico e prática pedagógica não lhe é desconhecida. Em contrapartida, comunicam também que ele não sabe como lidar com isso.

De modo geral, a análise do que escreveram os estudantes sobre apren- 
dizagens, formação e prática docente levou ao entendimento de que é preciso mais do que dominar conhecimentos a "transmitir" para ser professor. De acordo com Mizukami (1996, p. 63): "qualquer que seja o modelo de aprendizagem dominante no pensamento do professor, este terá grande influência nas atividades de interação em sala de aula e na forma como as informações são consideradas". Tais palavras se fazem acentuadas pelo que escreveu um dos sujeitos: "[...] creio que aprendi, com muitos dos meus professores de graduação, como não se deve dar aula, ou melhor, como eu gostaria que minhas aulas não fossem" (ALD5).

Enunciados como o que se segue inspiram reflexão sobre as aprendizagens de um curso chamado licenciatura.

Quando entrei no curso de matemática não queria fazer licenciatura. Uma certa vez, eu dei uma aula para uma criança que precisavam e adorei. Dar aula é uma "coisa" muito prazerosa; b) quase não tive aprendizagens sobre a profissão docente, no curso vemos mais teria [teoria] e de matemática pura e aplicada. A licenciatura "fica de lado"; c) nossa muitas coisas eu gostaria de ter aprendido. (AMD3)

No supracitado, o emprego do pronome "nossa" com a função de vocativo na expressão "nossa muitas coisas eu gostaria de ter aprendido" é significativo, ao acentuar a necessidade de aprendizagens do sujeito escrevente. A expressão "a licenciatura fica de lado" confirma essa interpretação.

\section{Formação e trabalho docente}

A análise desenvolvida no eixo que focaliza trabalho e formação docente tendeu para uma discussão sobre paradigmas educacionais. A esse respeito, Gamboa (1996, p. 123) argumenta: "dominar técnicas de ensino, ou processos didático-pedagógicos, ou mesmo conteúdos enciclopédicos não é suficiente. É necessário compreender a dinâmica da sociedade onde os processos educativos acontecem e dentro da qual tais processos têm sentido". O autor aponta a necessidade de superação daquilo que muito figurou no discurso dos sujeitos pesquisados, a saber: estratégias de ensino (ALD3), métodos (AMD2), processos didático-pedagógicos (AMD5, AMN3 e AMN2), conteúdos enciclopédicos (apontados por 14 estudantes).

Uma concepção linear e simplista de formação docente (PÉREZ GÓMEZ, 1992) desponta no discurso dos sujeitos da pesquisa. Isto se confirma pelas palavras que se seguem: “[...] quanto às aprendizagens sobre docência, estas 
foram mais abordadas nas matérias voltadas para a área de educação, no entanto, alguns professores sempre dão dicas de como podemos aplicar o conteúdo a ser estudado nas alas de aula de $5^{\mathrm{a}}$ série do EF ao $3^{\circ}$ ano do EM, sempre nos lembrando que seremos professores" (ALD1, grifos nossos). Constatou-se também que suas concepções não são claras a respeito do que seja a profissão para a qual se formam. Alguns, ao discorrerem sobre o curso, lamentam a oportunidade perdida: “[...] acho que aprendemos muita teoria e pouca prática. Gostaria de ter mais contato com a realidade das escolas" (AMD1). Outros são profiláticos:

O professor não deve se preocupar em apenas ir à sala de aula e passar o conteúdo científico aos alunos, ele também deve se preocupar com o social do aluno, o que o aluno vive fora da escola. O professor não está ali para apenas cumpir [sic] o conteúdo programático que o estado exija que ele cumpra, está ali para tornar seus alunos pessoas mais cultas, mais preocupadas com certas questões do nosso dia, mais dominadoras do saber. (AMD5)

Os saberes apontados pelos sujeitos como importantes à profissão (eixo 4) contrapõem-se aos conhecimentos apontados como necessários ao ensino de conteúdos de Língua Portuguesa e Matemática (eixo 5). Para além das discrepâncias e desencontros conceituais, o aluno permanece como o centro das atenções dos futuros professores pesquisados (a análise apresentada no eixo 5 confirma o verificado na análise do eixo 1).

Experiência docente: formação que transcende os estreitos limites da sala de aula da universidade

Motivados pela lembrança dos momentos passados na escola, os sujeitos pesquisados relataram passagens que marcaram a sua trajetória de formação (eixo 6), analisando criticamente situações vividas e assumindo posições ideológicas em relação aos variados fatores que permeiam e constituem não somente o ambiente de ensino da instituição escolar, mas a eles próprios, enquanto professores e/ou futuros professores. A dificuldade em discorrer com propriedade sobre educação e ensino (verificada no eixo 2) desaparece (no eixo 6), quando questões relativas a essas temáticas emergem da história singular de cada sujeito.

Boas ou ruins, as experiências vividas por cada um dos vinte estudantes de licenciatura pesquisados passaram a constituí-los de modo decisivo, motivandoos ou desestimulando-os a prosseguir na carreira escolhida. $\mathrm{O}$ relato de uma 
estudante a respeito de suas experiências como professora e como estagiária ilustra bem isso.

O que fazemos é uma tentativa frustrada e um desgaste emocional intenso para educar (no sentido de "dar berço") os [aos] alunos, uma vez que os pais delegaram tal responsabilidade para a escola. No caso da escola pública, pior, pois além disso, somos constantemente ameaçados. Viramos na verdade, uma descarga das frustrações dos alunos que não conseguem aprender e não vêem sentido nisto e portanto destrata [destratam] o professor a todo momento. Eu me desiludi totalmente e profundamente com a profissão do professor. (ALN4)

O lugar chamado sala de aula não é uma incógnita, é o resultado da interação de múltiplos fatores. Sua complexidade é algo que, há tempos, desafia o professor, especialmente os novatos, que necessitam de tempo e de oportunidades para aprender (MIZUKAMI et al., 2002). Oportunidades que poderiam extrapolar os limites formação inicial. Talvez fosse o caso de se considerar a possibilidade de os futuros professores passarem por processo semelhante ao que dos estudantes de Medicina nos períodos de residência médica. Uma outra opção seria criar uma escola para crianças e jovens dentro da própria universidade, a exemplo da que existe na Faculdade de Educação da USP. Nessa escola, o futuro professor poderia aprender a partir de necessidades formativas reais, articulando formação teórica e prática. De todo o modo, Marcelo García (1997, p. 55) esclarece: "não se deve pretender que a formação inicial ofereça 'produtos acabados', encarando-a antes como a primeira fase de um longo e diferenciado processo de desenvolvimento profissional".

Possibilidades à parte, a análise (eixo 6) confirma o que a literatura educacional vem apontando: existem contrastes entre o que se aprende nos anos de formação inicial e o que se verifica na escola como professor ou estagiário (LIMA; REALI, 2002; MIZUKAMI et al., 2002; MARCELO, 1998). Confirma também que aprendizagens oriundas da vivência na escola de ensino fundamental e/ou médio são um diferencial no processo de formação do professor.

A seguir, serão apresentados os resultados finais da pesquisa. Alguns poderão coincidir com aspectos já apontados nesta seção. 


\section{Resultados}

A análise desenvolvida no eixo "Professor: da teoria à prática de sala de aula" (eixo 1), possibilitou constatar que: 1) os futuros professores preocupamse primeiramente com o aluno e com questões correlatas; 2) para a maioria dos estudantes pesquisados o professor é um educador movido por valores e ideais; 3) os estudantes pesquisados não reconheceram teorias educacionais subjacentes à ação pedagógica de um professor em situação específica (aula diferente). Essas constatações sugerem que os momentos iniciais desses sujeitos na carreira poderão ser não muito tênues, visto que insegurança, idealização e reduzido grau de conhecimento teórico são elementos que em nada contribuem para minimizar o desconforto gerado pela condição de iniciante na profissão. Os estudantes pesquisados demonstraram antever e temer as situações conflitivas que haverão de enfrentar na escola.

A análise desenvolvida em "A relevância das concepções do professor na prática educativa" (eixo 2 ) evidenciou que os quase professores explicam educação e ensino por meio da doxa e não da episteme. Tal evidência propõe pensar sobre a prática educativa de um professor que conclui a sua formação inicial para a docência sem ter clareza sequer do que seja educação e ensino. Esse fato adquire gravidade à luz da premissa de que o que o professor pensa sobre o ensino influi fortemente naquilo que faz em sala de aula (MARCELO GARCIA, 1997; MIZUKAMI et al., 2002).

No eixo "O papel do professor na gestão escolar" (eixo 3), constatou-se que os estudantes pesquisados não só não reconhecem a escola como lugar de ação coletiva, como também não fazem nenhuma referência à gestão escolar propriamente dita, apesar de discorrerem sobre ela. Desconhecem, portanto, educação, ensino e gestão: três conceitos básicos para o professor saber o quê, por quê, para quê, para quem, de que modo e em que lugar atua. Tal evidência sugere turbulências nos contatos iniciais com a escola, local cuja realidade imediata e imprevisível constitui, por si só, um desafio.

Em "Saberes e formação docente" (eixo 4), constatou-se que os saberes aprendidos, majoritariamente os do conteúdo a ensinar, não são o foco dos estudantes do último ano de licenciatura, mas sim os não aprendidos. Atentos àquilo que gostariam de ter aprendido na formação inicial, evidenciaram a criticidade como um aspecto positivo de sua formação.

Das constatações obtidas em "Formação e trabalho docente" (eixo 5), destaca-se a de que o futuro professor afirma em alguns momentos aquilo que nega em outros: num dado momento da investigação, critica a sua formação 
pela ausência de saberes do campo da educação, saberes que classifica como fundamentais à profissão (eixo 4), num outro, (eixo 5), declara que importantes para ensinar Língua Portuguesa ou Matemática são os saberes privilegiados no curso que o tem formado, saberes centrados nos conhecimentos específicos da matéria a ensinar.

As constatações resultantes da análise desenvolvida em "Experiência docente: formação que transcende os estreitos limites da sala de aula da universidade" (eixo 6) coincidem com as da análise empreendida em "Saberes e formação docente" (eixo 4): os estudantes enfatizam os saberes relativos à educação como os necessários à sua formação/atuação profissional, com o diferencial de que, ao discorrerem sobre as suas idiossincráticas experiências na escola, expuseram seus pontos de vista com mais autonomia, o que ampliou o grau de criticidade presente em seus enunciados.

\section{Conclusões}

O desafio de formar um profissional para o exercício de uma atividade tão complexa como a docência existe, justificando a questão que motivou esta investigação. Se a formação do professor não se inicia com os anos de licenciatura, também não se encerra com a conclusão desta. Enquanto parte de um processo formativo mais amplo, os anos de licenciatura podem contribuir fortemente, decisivamente, para a segurança do professor em sala de aula, conferindo-lhe clareza sobre a sua função social e escolar.

Investigadas as concepções de futuros professores sobre a profissão para a qual estão praticamente formados, entendeu-se que os saberes necessários ao professor para que tenha mais domínio e menos dificuldades em sala de aula são aqueles que lhe confiram segurança no ato de educar, no caso, saberes relativos à especificidade da profissão e saberes relativos ao contexto sócio-histórico no qual ela acontece.

Os futuros professores pesquisados veem o professor como um educador que necessita de conhecimentos específicos para lidar com um sujeito chamado aluno. A sala de aula os desafia, não sendo boas as suas expectativas quanto ao que encontrarão na escola. Pelo que evidenciou a pesquisa, a ausência de saberes tipicamente educacionais fizeram a diferença na formação dos estudantes pesquisados. Embora receosos e inseguros, em breve estarão na escola, atuando como professores e sobrevivendo ao desafio de ensinar em condições adversas, contando apenas com as aprendizagens de uma formação inicial centrada numa 
realidade que não é a da escola de ensino fundamental e médio para a qual se dirigirão.

A investigação apresentada neste trabalho autoriza a afirmar que as licenciaturas focalizadas formam o professor, mas, nesse processo, não privilegiam os saberes relativos à especificidade da função docente. Assim procedendo, limitam as chances de sucesso e ampliam as chances de fracasso do professor antes mesmo de ele ingressar na profissão, gerando perdas que recairão sobre a prática educativa desse profissional e, consequentemente, sobre a aprendizagem de seu aluno.

\section{Considerações finais}

Sem pretender defender a formação inicial do professor, tampouco hierarquizar os tipos de formação oferecidos pela universidade, a investigação apresentada propõe pensar uma formação que reduza o desencanto e a frustração sofridos por um profissional cujo destino é a escola. Partindo-se da premissa de que a formação universitária não constitui mero produto a ser "substituído" a posteriori, e de que seja este um período-chave para o sucesso de aprendizagens subsequentes, sugere-se um olhar mais atento a iniciativas como a de André (1996) e seu garimpo teórico ${ }^{2}$.

Numa época em que se prevê o redimensionamento da formação docente por meios tecnológicos (PRADO; VALENTE, 2002), a escola, enquanto campo de atuação do professor, não pode mais figurar como estranha ameaça àquele que frequenta o último ano de uma formação inicial para a docência. Caso isto ocorra, da universidade à escola, o choque entre o estudado e o vivido se fará,

2 André (1996) propõe desenvolver junto aos alunos atividades de reanálise da prática escolar e de reflexão sobre o processo de pesquisa, para que se tornem leitores críticos da própria prática. Sugere "garimpar a literatura educacional para fundamentar as leituras desses aspectos críticos, fugindo das conclusões apressadas e superficiais" (p. 104). 
uma vez mais, inevitável (LIMA, 2004; FREITAS, 2002).

\section{REFERÊNCIAS}

ALONSO, M. A gestão/administração educacional no contexto da atualidade. In: VIEIRA, A. T.; ALMEIDA, A. M. (Orgs.). Gestão educacional e tecnologia. São Paulo: Avercamp, 2003. p. 23-38.

ANDRÉ, M. E. D. A. O papel da pesquisa na formação do professor. In: REALI, A. M. M. R.; MIZUKAMI, M. G. N. Formação de Professores: tendências atuais. São Carlos: EdUFSCar, 1996. p. 95-105.

BARRETTO, R. G. Tecnologias na formação de professores: o discurso do MEC. Educação e Pesquisa, v. 29, n. 2, p. 271-286, 2003.

BARROS, A. J. S; LEHFELD, N. A. S. Fundamentos de metodologia científica: um guia para a iniciação científica. São Paulo: Makron Books, 2000.

FREITAS, M. N. C. Organização escolar e socialização profissional de professores iniciantes. Cadernos de Pesquisa, n. 115, p. 155-172, 2002.

GAMBOA, S. S. A contribuição da Pesquisa na formação docente. In: REALI, A. M. M. R.; MIZUKAMI, M. G. N. Formação de professores: tendências atuais. São Carlos: EdUFSCar, 1996. p. 115-130.

LELIS, I. A. Do ensino de conteúdos aos saberes do professor: mudança de idioma pedagógico? Educação \& Sociedade, ano XXII, n. 74, 2001.

LIBÂNEO, J. C. Organização e gestão da escola. Goiânia: Alternativa, 2004.

. Organização e gestão da escola: teoria e prática. Goiânia: Alternativa, 2001.

LIMA, E. F. A construção do início da docência: reflexões a partir de pesquisas brasileiras. Revista Centro de Educação, Laboratório de Pesquisa e Documentação (Lapedoc), Santa Maria, v. 29, n. 2, 2004.

LIMA, S.; REALI, A. M. M. R. O papel da formação básica na aprendizagem profissional da docência (aprende-se a ensinar no curso de formação básica?). In: MIZUKAMI, M. G. N.; REALI, A. M. M. R. (Orgs.). Formação de professores, práticas pedagógicas e escola. São Carlos: EdUFSCar, 2002. p. 217-235.

MANTOAN, M. T. E. Abrindo as escolas às diferenças. In: MACHADO, N. J. et al. 
Pensando e fazendo educação de qualidade. São Paulo: Moderna, 2001. p. 109-128. MARCELO, C. Pesquisa sobre a formação de professores: o conhecimento sobre aprender a ensinar. Revista Brasileira de Educação, n. 9, p. 51-75, 1998.

MARCELO GARCIA, C. A formação de professores: novas perspectivas baseadas na investigação sobre o pensamento do professor. In: NÓVOA, A. (Coord.). Os professores e a sua formação. Lisboa: Dom Quixote, 1997. p. 53-75.

MIZUKAMI, M. G. N. Docência, trajetórias pessoais e desenvolvimento profissional. In: REALI, A. M. M. R.; MIZUKAMI, M. G. N. Formação de professores: tendências atuais. São Carlos: EdUFSCar, 1996. p. 59-91.

. Ensino: as abordagens do processo. São Paulo: EPU, 1986.

MIZUKAMI, M. G. N. et al. Escola e aprendizagem da docência: processos de investigação e formação. São Carlos: EdUFSCar, 2002.

PÉREZ GÓMEZ, A. O pensamento prático do professor: a formação do professor como profissional reflexivo. In: NÓVOA, A. (Org.). Os professores e a sua formação. Lisboa: Dom Quixote, 1992. p. 95-114.

PRADO, M. E. B. B.; VALENTE, J. A. A educação à distância possibilitando a formação do professor com base no ciclo da prática pedagógica. In: MORAES, M. C. (Org.). Educação à distância: fundamentos e práticas. Campinas: Unicamp/Nied, 2002. p. $27-50$.

TARDIF, M. Saberes docentes e formação profissional. Petrópolis: Vozes, 2002.

Texto recebido em 25 de julho de 2008.

Texto aprovado em 11 de março de 2009. 